\title{
Neocortical development as an evolutionary platform for intragenomic conflict
}

\author{
Eric Lewitus* and Alex T. Kalinka \\ Max Planck Institute of Molecular Cell Biology and Genetics, Dresden, Germany
}

\section{Edited by:}

Iva Kelava, Max Planck Institute of Molecular Cell Biology and

Genetics, Germany

Reviewed by:

Alino Martinez-Marcos, Universidad

de Castilla, Spain

Guy Elston, Centre for Cognitive

Neuroscience, Australia

*Correspondence:

Eric Lewitus, Max Planck Institute of Molecular Cell Biology and

Genetics, Pfotenhauerstr. 108,

01307 Dresden, Germany.

e-mail: lewitus@mpi-cbg.de
Embryonic development in mammals has evolved a platform for genomic conflict between mothers and embryos and, by extension, between maternal and paternal genomes. The evolutionary interests of the mother and embryo may be maximized through the promotion of sex-chromosome genes and imprinted alleles, resulting in the rapid evolution of postzygotic phenotypes preferential to either the maternal or paternal genome. In eutherian mammals, extraordinary in utero maternal investment in the brain, and neocortex especially, suggests that convergent evolution of an expanded mammalian neocortex along divergent lineages may be explained, in part, by parent-of-origin-linked gene expression arising from parent-offspring conflict. The influence of this conflict on neocortical development and evolution, however, has not been investigated at the genomic level. In this hypothesis and theory article, we provide preliminary evidence for positive selection in humans in the regions of two platforms of intragenomic conflict-chromosomes $15 q 11-q 13$ and $X$-and explore the potential relevance of cis-regulated imprinted domains to neocortical expansion in mammalian evolution. We present the hypothesis that maternal- and paternal-specific pressures on the developing neocortex compete intragenomically to influence neocortical expansion in mammalian evolution.

Keywords: parent-offspring conflict, evolution, neocortex, genomic imprinting, X-chromosome, development, mammals

\section{PARENT-OFFSPRING CONFLICT AT THE FETAL-PLACENTAL INTERFACE}

Development of the fetal-placental interface, which gives the fetus direct access to manipulate the availability of maternal resources, is a cardinal event in the evolution of viviparous mammals. Furthermore, while viviparity has evolved in other vertebrate taxa (e.g., Squamata), the transition from oviparity (egg-laying) to viviparity has been institutionalized in mammals, such that no species has transitioned back to oviparity in 200 million years (Killian et al., 2001a,b; Meredith et al., 2011). Importantly, evolution of the fetal-placental interface in mammals has established a unique genomic platform for conflict, or sometimes coadaptation (Curley et al., 2004; Wolf and Hager, 2006), between the fetal and maternal genomes. And the munitions employed in that conflict are genomic imprinting and $\mathrm{X}$-linked gene expression.

Imprinted genes are inherited biparentally in the fetal genome, but during gametogenesis these genes are epigenetically modified to express only one parental allele in zygotic development (Li et al., 1999; Reik and Walter, 2001). In most cases, imprinted genes occur in a cluster (Williamson et al., 2006) and are controlled by a tissue- and temporal-specific cis-acting regulatory element, the so-called imprinting control element (ICE), that is imprinted on a parental-specific allele by DNA methylation or histone modification (Santoro and Barlow, 2011). Maintenance of the imprint is regulated in the embryo by either CTCFdependent insulators or long non-coding RNAs (Sleutels and Barlow, 2002; Lewis and Reik, 2006; Mancini-Dinardo et al.,
2006; reviewed in Bartolomei and Ferguson-Smith, 2011), the deletion of which results in regional loss of imprinting (Wutz et al., 1997; Thorvaldsen et al., 1998; Fitzpatrick et al., 2002; Lin et al., 2003; Williamson et al., 2006). While not all viviparous taxa show evidence for genomic imprinting (e.g., species of fish), imprinting is ubiquitous in viviparous mammals (Lawton et al., 2005; Renfree et al., 2009). The deep conservation of viviparity and imprinting in mammals emphasizes both the profound integration of the fetus into the apportioning of maternal resources through the maternal-fetal interface, as well as the considerable inclusive-fitness asymmetry in the contribution of parental resources. Importantly, neurological diseases associated with imprinted domains show divergent symptoms depending on the parent-of-origin of the imprinted allele (Crespi, 2008; Ubeda and Wilkins, 2008).

The phenomenon of conserved genomic imprinting in mammals has been subsumed into a more general theory of mammalian evolution, Parent-Offspring Conflict (Trivers, 1974; Moore and Haig, 1991; Wilkins and Haig, 2003). This theory describes, with formidable accuracy, how maternal and paternal interests, particularly in polygamous societies, may compete intragenomically over the allocation of resources to the fetus. That is, when a gene affects the fitness of an individual to whom the maternally inherited and paternally inherited alleles have different degrees of relatedness, the optimal strategy of each allele will depend on its parent-of-origin. In the case of multiple paternity, the paternal genome is more concerned 
with maximizing maternal resource allocation to the fetus at the expense of future (unrelated) progeny, whereas the primary interest of the maternal genome is to allocate resources evenly to all (equally related) progeny. Therefore, genes involved in parent-offspring conflict and the allocation of maternal resources should overlap with genes prone to evolving imprinted expression. Unsurprisingly, loci that influence embryonic growth (e.g., Igf2, Stox1, and genes involved in secreting placental lactogens) and cell division (e.g., Aspm, Erbb3) are often associated with imprinted genes (Haig, 1993; Tycko and Morison, 2002; Reik et al., 2003; Constância et al., 2004; Oudejans et al., 2004; Arngrímsson, 2005; van Dijk et al., 2005; Singhmar and Kumar, 2011). In the case of the brain, and the mammalian neocortex in particular, the involvement of imprinting centers of the latter type may be especially important for their effect on neurogenesis for two reasons: mammals with relatively high metabolic rates do not produce relatively large-brained progeny ( $\mathrm{McNab}$, 1989; Harvey and Krebs, 1990), as would be expected if brain size were determined strictly by maternal metabolic rates and access to maternal nutrient transfer (Lewitus et al., 2012b); and genomic loci governing variation in brain and body size are largely independent (Hager et al., 2012), so evolutionary changes in brain size cannot be primarily arbitrated by embryonic growth factors, but must be responsive to brain size-specific selection pressures decoupled from overall embryonic growth. Here, we discuss two genomic platforms for parent-offspring conflict in neocortical evolution: genomic imprinting at human chromosome 15q11-q13 and the human X-chromosome. We focus specifically on brain-expressed genes and, based on a review of the literature as well as preliminary analyses presented here, propose a major role for genomic imprinting and $\mathrm{X}$-linked gene expression, regulated by cis-acting long noncoding RNAs, in the evolution of an expanded mammalian neocortex.

\section{HUMAN CHROMOSOME 15q11-q13}

A disproportionate number of imprinted genes are expressed, sometimes exclusively, in the brain (Wilkinson et al., 2007). While it was, at first, indicated that maternally inherited genes showed a bias for expression in the cortex and paternally inherited genes showed a bias in the hypothalamus (Keverne et al., 1996), recent evidence has demonstrated this not to be the case. In fact, 70\% of imprinted genes in the preoptic area and medial prefrontal cortex of the mouse show a bias for expression of the paternal allele (Gregg, 2010). On human chromosome 15q11-q13, several brainspecific genes are expressed exclusively from the paternally inherited allele and only two genes, Ube3a and Atp10a, are expressed from the maternally inherited allele (Chamberlain and Lalande, 2010); these paternally and maternally inherited genes are controlled by the Prader-Willi Syndrome (PWS) and Angelman Syndrome (AS) imprinting centers, respectively (Saitoh et al., 1996). Ube3a is present in the nucleus and cytoplasm, observed only in neurons, and can ubiquitylate the DNA-repair and cellcycle progression proteins HHR23 and MGMT, thereby targeting their destruction (Reis et al., 1994; Albrecht et al., 1997; Kumar et al., 1999; Srivenugopal and Ali-Osman, 2002; Le Meur et al., 2005; Dindot et al., 2008). It has recently been shown that Ube3a interacts with the microcephaly-related gene Aspm, possibly by regulating HHR23 in S-phase, and that knockdown of Ube3a leads to increased apoptosis due to chromosome missegregation and abnormal spindles (Singhmar and Kumar, 2011). In normal eutherian development, maternal expression of Ube3a is regulated by the paternally inherited long non-coding antisense RNA (LNCAT), Ube3a-ATS, that encompasses Snurf-Snrpn, Snord116, Snord115, and extends to Ube3a (Rougeulle et al., 1998; Runte et al., 2001; Landers et al., 2004; Rapkins et al., 2006). Because the AS imprinting center represses the PWS imprinting center on the maternal allele (Brannan and Bartolomei, 1999), when the former is mutated or deleted the latter loses its DNA methylation imprint. This results in the epigenetic silencing of the maternal Ube3a and causes neurodevelopment to proceed without ubiquitin ligase, ultimately leading to AS, a heritable disorder characterized by microcephaly (Kishino et al., 1997; Yamasaki et al., 2003). Likewise, when the paternal PWS imprinting center is mutated or deleted, neurodevelopment is disrupted, resulting in PWS, a disorder complemented by, among other pathologies, cognitive impairment (Cassidy and Driscoll, 2009).

\section{HUMAN X-CHROMOSOME}

The X-chromosome has evolved a preferential role in regulating brain development (Nguyen and Disteche, 2006; Swingland et al., 2012). This is evident, not only from genomic imprinting, but also in the evolution of brain-specific X-linked genes. The case of X-linked genomic imprinting is distinct from autosomal imprinting, because X-chromosome inheritance is biased by the sex of the fetus. That is, traits conferred by paternally expressed $\mathrm{X}$-linked genes will only be heritable in females, whereas those conferred by maternally expressed X-linked genes will be heritable by both males and females. Nonetheless, effects of genomic imprinting in $45, \mathrm{X}^{\mathrm{m}}$ (single $\mathrm{X}$-chromosome of maternal origin) and $45, \mathrm{X}^{\mathrm{P}}$ (single $\mathrm{X}$-chromosome of paternal origin) individuals have proven to be considerable (Davies et al., 2006) and may, furthermore, reveal biases in the inheritance patterns of paternal versus maternal traits. $45, \mathrm{X}^{\mathrm{m}}$ individuals, for example, show larger superior temporal gyrus volume, but reduced gray matter in the caudate nuclei and white matter in the temporal lobes compared to $45, \mathrm{X}^{\mathrm{p}}$ individuals (Skuse et al., 1997). An explanation for this difference has implicated the Xlr gene family, which is imprinted with spatial- and temporal-specificity in the brain. Specifically, although evidence is scant, Xlr genes may influence brain plasticity during development by facilitating the rearrangement of protocadherins, genes that mediate cell adhesion, cytoskeletal organization, and morphogenesis, and are widely expressed throughout the brain (Frank and Kemler, 2002). Interestingly, only a subset of Xlr genes are imprinted in mouse compared to human, despite high sequence conservation (Davies et al., 2006).

Evidence for X-chromosome significance in regulating brain development is shown in its ability to disrupt neurodevelopment and the resulting pathologies. Fragile X syndrome (FXS) is a common form of inherited mental retardation (Laxova, 1994; Penagarikano et al., 2007). It is caused by the transcriptional silencing via hypermethylation of the $5^{\prime}$ UTR of Fragile X Mental Retardation 1 (FMR1), a RNA-binding protein involved 
in localized translation of target mRNAs (Fu et al., 1991; Oberle et al., 1991; Verkerk et al., 1991). The FMR1 protein is especially enriched in neurons and has been linked to the regulation of neural stem and progenitor cell proliferation during neurogenesis (Abitbol et al., 1993; Devys et al., 1993; Hinds et al., 1993; Callan and Zarnescu, 2011). FMR1-deficient mice show a 3-fold increase in neurons, including an increased population of Tbr2+ cells in the ventricular zone (VZ) and subventricular zone (SVZ) at embryonic day 17 (Castrén et al., 2005) and neural progenitor cells in cortical layers adjacent to the lateral ventricle (Tervonen et al., 2009), resulting in increased cell density in layer $\mathrm{V}$ of the postnatal neocortex. Likewise, FXS human embryos show a 5-fold increase in neurons, as well as notable gene expression changes, including an upregulation of Erbb3 and the maternally imprinted Diras3 (Bhattacharyya et al., 2008) and an enlargement of the caudate nuclei (Reiss et al., 1995; Eliez et al., 2001; Lee et al., 2007; Hoeft et al., 2008; Hazlett et al., 2009). Saffary and Xie (2011) recently showed that FMR1 utilizes an actin-dependent mechanism to control the ratio of radial glia (RG) and intermediate progenitor cells (IPs) during neurogenesis, suggesting that the observed increase in neurons is due to a shift in the relative ratio of RG to IPs during neocortical development. Evidence that FMR1 is involved in the translational control of Tbr2 may also help explain why FMR1-deficiency leads to increased SVZ density in mice (Tervonen et al., 2009) and enlarged ventricle size in humans (Mostofsky et al., 1995; Reiss et al., 1995).

\section{NEUROGENIC GENE EXPRESSION AND EVIDENCE FOR SELECTION IN IMPRINTED DOMAINS}

As a preliminary investigation into whether parent-of-originlinked genes may play a role in neocortical evolution, we tested several selection models on imprinted genes, in addition to their long intergenic non-coding neighbors (lincRNAs), that are differentially expressed during human and/or mouse cortical neurogenesis.

\section{PERVASIVE PURIFYING SELECTION IN IMPRINTED AND X-LINKED NEUROGENIC GENES}

We retrieved RNA-seq data sampled prenatally from mouse and human neocortical germinal zones via the Gene Expression Omnibus (accession no. GSE38805) and analyzed differentially expressed coding (Anders and Huber, 2010) and non-coding (Cabili et al., 2011) transcripts. Imprinting status was determined for 49 differentially expressed genes at www.geneimprint.com (see Table A1). We collected multiple alignments of nucleotide sequences for at least 30 species, including one non-mammalian (Gallus gallus) and/or noneutherian (Macropus eugenii, Monodelphis domestica, and/or Ornithorhynchus anatinus) outgroup, for the 49 imprinted genes, FXS-related Erbb3, and paternally imprinted Usf1, a transcription factor that interacts with the FMR1 promoter (Kumari and Usdin, 2001). Gene trees were constructed using a maximumlikelihood approach (Phylip v3.69) and analyzed in HyPhy (v2.1.2), which uses a branch-site model for detecting episodic diversifying selection along lineages (Kosakovsky Pond et al., 2011) and codon-based maximum-likelihood to estimate dN/dS at specific codon alignments (Kosakovsky Pond, 2005). These tests assume that substitutions can be described by a parameterized continuous-time Markov process and thereby model episodic selection in the substitution rates along lineages that may vary across both genomic sites (i.e., codons) and phylogenetic branches (Anisimova and Yang, 2007; Anisimova and Kosiol, 2009; Delport et al., 2010a,b; Yang and dos Reis, 2011).

The protein-coding genes investigated (Figure 1; Table A1) were predominantly under pervasive purifying selection in both mouse and human (Figure 2). In total, 29\% of genes were found to have undergone diversifying selection along one or more branches (Figure 3). According to our selection criteria, no significant differences were found between maternally and paternally imprinted genes (Figure 4). The observed level of purifying selection in these genes is consistent with previous work showing disease genes, both complex and Mendelian, to be under greater purifying selection, based on substitution rate $(\mathrm{dN} / \mathrm{dS})$ as well as single nucleotide polymorphism data $(\mathrm{Pn} / \mathrm{Ps})$, than non-disease genes (Blekhman et al., 2008; Cai et al., 2009). That any disruptive mutation in these genes leads to severe disease phenotypes may explain both their intolerance to any deleterious mutations and strong need to be under pervasive purifying selection. This hypothesis, of course, does not take into account the considerable interspecific diversity in cortical organization (Butti et al., 2011; Lewitus et al., 2012a), but rather relates directly to neuron generation, a process that may be considered largely conserved in mammals (Franco and Müller, 2013). It moreover highlights the importance of non-coding regions, located in or nearby the imprinted domains, to differentially regulate the expression patterns of parent-of-origin-specific alleles in different species.

\section{SELECTIVE CONSTRAINTS IN INTERGENIC NON-CODING REGIONS OF IMPRINTED DOMAINS}

On human chromosome 15q11-q13 the LNCAT Ube3a-ATS encompasses Snurf and Ube3a and represses expression of the paternally inherited copy of $U b e 3 a$. Three lincRNAs reside in this

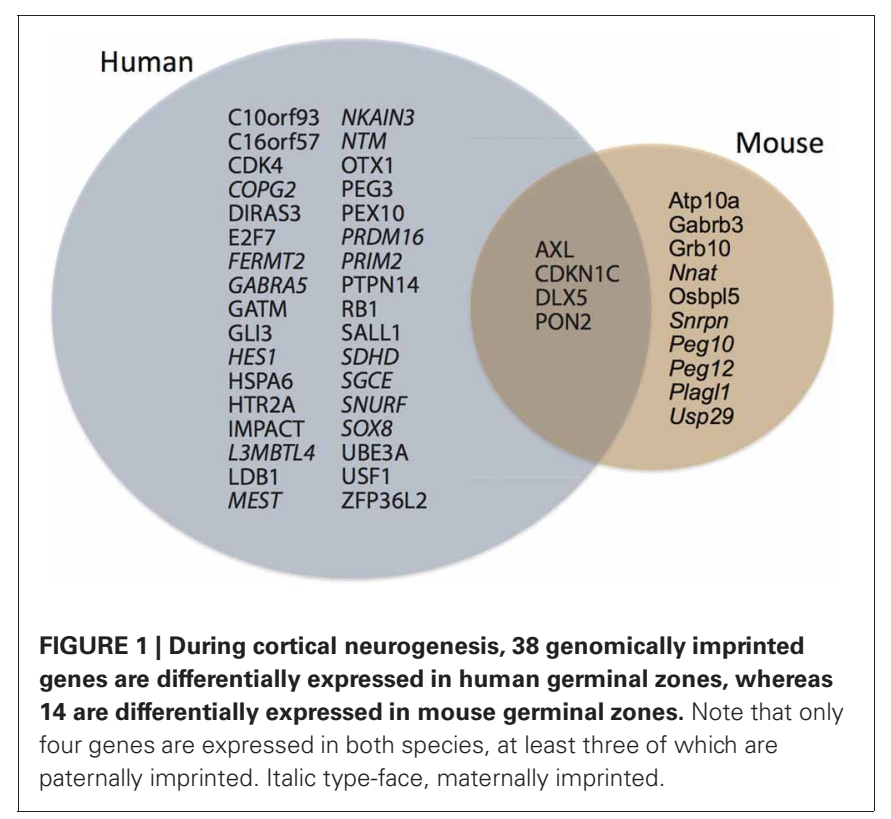



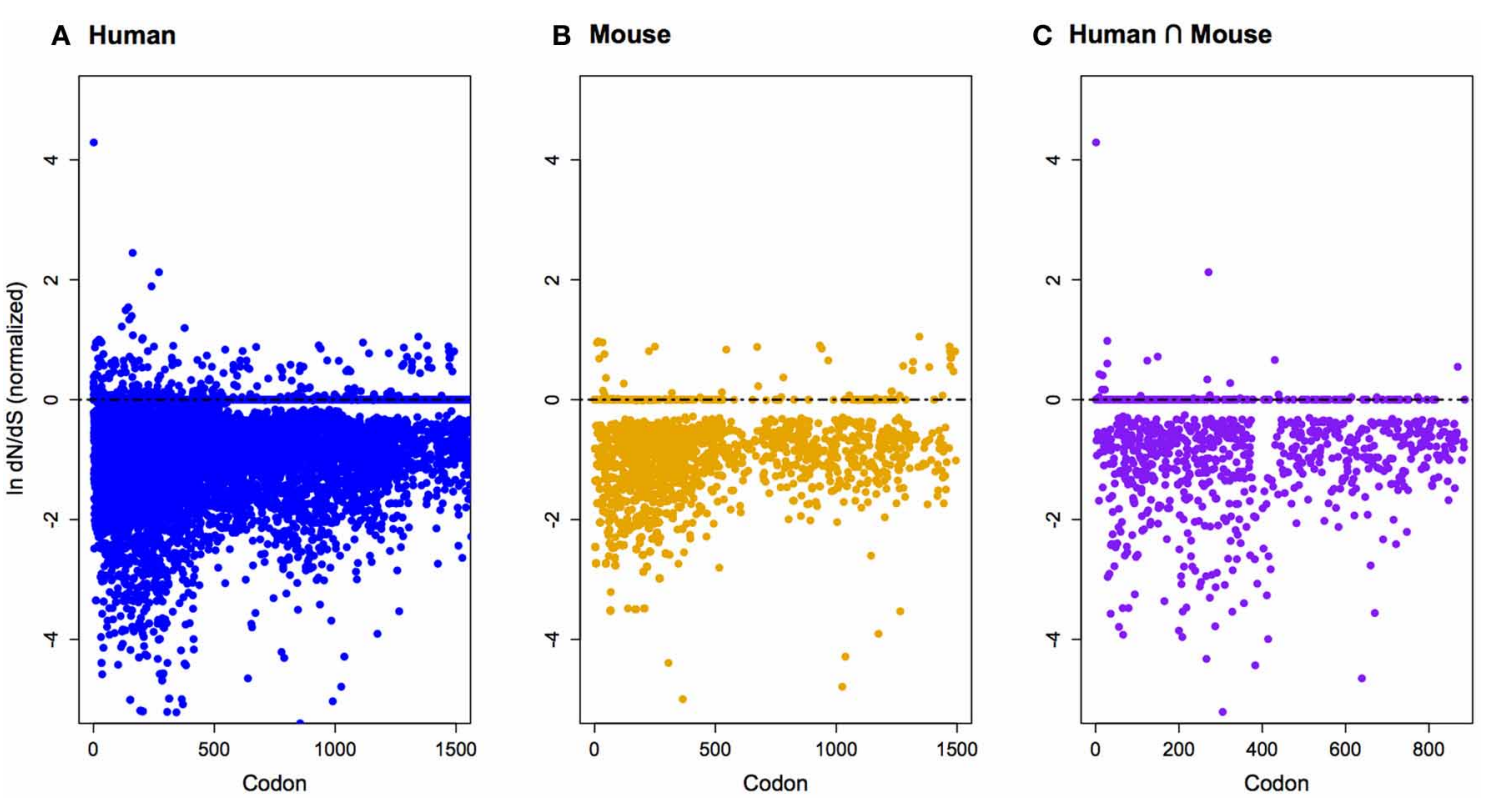

FIGURE 2 | Normalized In-transformed dN/dS scores at each codon site for imprinted genes differentially expressed during cortical neurogenesis in only human (A), only mouse (B), and both human and mouse (C). Note that genes are predominantly under pervasive purifying selection. See Table A1 for a list of genes region, one of which exhibits upregulated expression in human embryos relative to the mouse (unpublished observation). To explore the selective pressures that might be acting on these noncoding RNAs, we downloaded human SNP data generated by The 1000 Genomes Project Consortium (2011) for the entire 15q11-q13 region (Figure 5A) and calculated Tajima's D statistic (Tajima, 1989) in a $10 \mathrm{~Kb}$ sliding window with a $2 \mathrm{~Kb}$ overlap. Negative values of Tajima's $D$ indicate that there is an excess of low frequency polymorphisms (relative to the neutral expectation), whereas positive values indicate that there is an excess of intermediate-frequency polymorphisms.

The results show that the region bounded by Snurf and Ube3a has an excess of low frequency polymorphisms relative to the rest of the region (Figure 5B). To test whether this was the result of purifying selection, and therefore indicative of a conserved region, we downloaded two additional metrics (PhyloP and PhastCons) which measure, in distinct ways, the extent of nucleotide conservation across species for a genomic region. PhyloP measures conservation at individual sites without taking into account flanking regions. Positive values of this metric indicate conservation and negative values indicate faster divergence than expected under neutral drift. PhastCons, on the other hand, measures only conservation (probabilities between 0 and 1 with higher values indicating more conservation), and in addition takes into account flanking regions and hence is ideal for discovering functional elements. Notably, all genes located on human chromosome 15q11-q13, with the exception of Atp10a, are differentially expressed during human cortical neurogenesis.

In the region bounded by Snurf and Ube3a, PhyloP takes some of the largest negative values for the entire 15q11-q13 region, indicating that there is accelerated divergence of nucleotides across species within this region (Figure 5C). The values for PhastCons, however, do not deviate strongly from other regions, indicating that this region is not experiencing strong purifying selection across species (Figure 5D). Taken together, these results suggest that this region has undergone adaptive evolution in humans or experienced a selective sweep at some point in our recent past. To explicitly test whether the region bounded by Snurf and Ube3a exhibits a signature of adaptive evolution in humans, we applied a McDonald-Kreitman test (McDonald and Kreitman, 1991) on the numbers of polymorphic SNPs and divergent bases (relative to the chimpanzee) in the lincRNA sequences relative to silent-site polymorphism and divergence in the closelylinked Snurf, Ube3a, and Atp10a coding regions. After applying a Jukes-Cantor correction for sequence homoplasy to the divergent counts (Jukes and Cantor, 1969), we find strong evidence for an excess of divergence relative to polymorphism for the lincRNAs $\left(P=6.72 \times 10^{-8}\right.$; Table 1$)$. The fraction of divergent bases that we estimate to be under positive selection in the lincRNAs, $\alpha$ (Smith and Eyre-Walker, 2002), is 0.764, an extremely high estimate. It remains possible that the excess of low frequency polymorphisms in the human data is the result of a selective sweep, and therefore SNP data from non-human species may help to shed light on the evolutionary forces acting on this region.

\section{Selective conservation of lincRNA in large-brained species}

Our analysis of the non-coding elements residing in the Ube3a imprinting domain reveals a potential importance for cis-regulated gene-expression in neocortical expansion. To assess whether lincRNA may be generally implicated in mammalian 


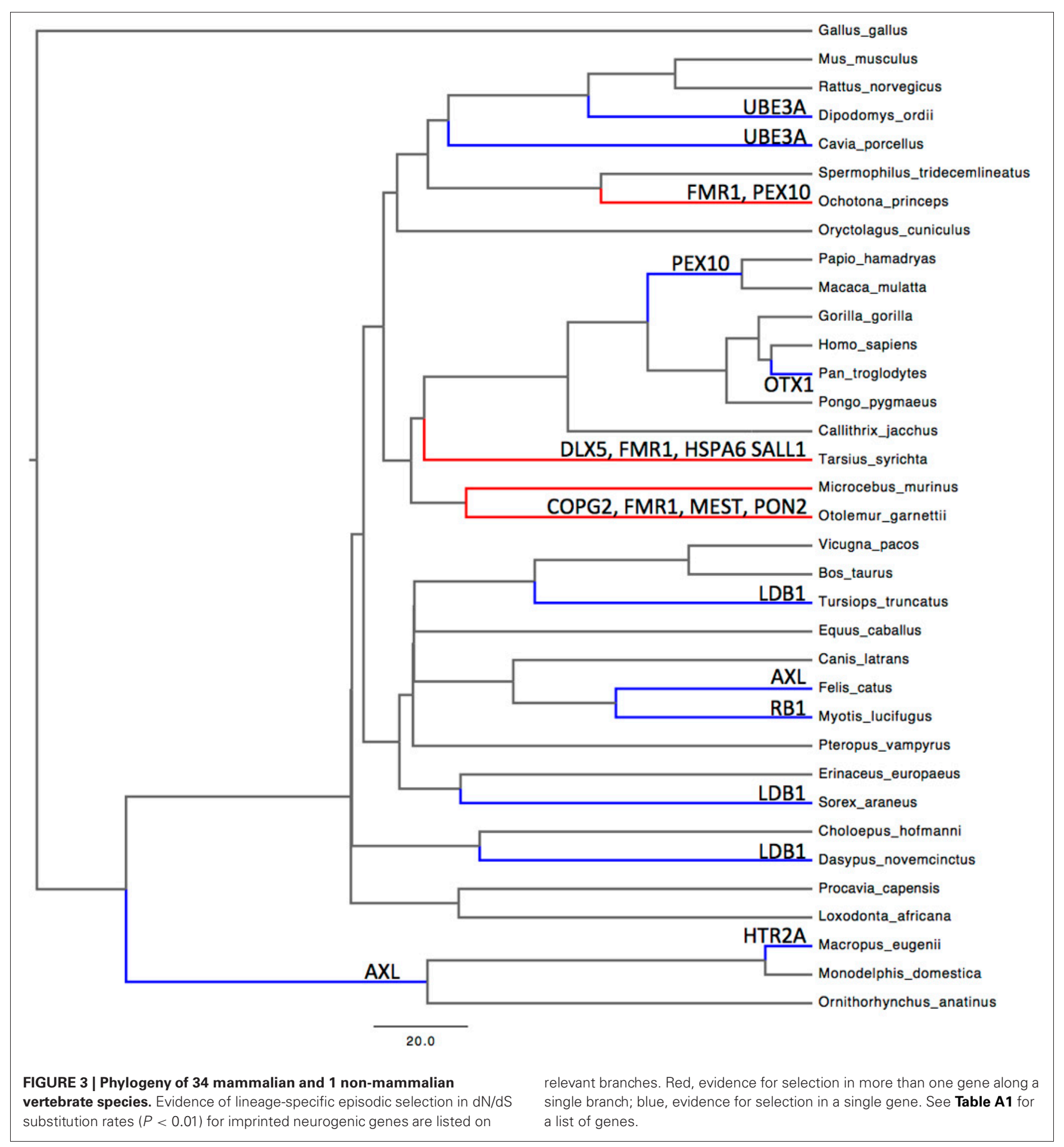

neocortical expansion, we took a broader perspective on differential gene regulation as it relates to neurodevelopment. Because lincRNA are often characterized as acting in cis (Ørom and Shiekhattar, 2011), the protein-coding neighborhood of the non-coding gene may be considered integral to its function. Therefore, we examined the genomic context of 161 lincRNAs expressed during the peak of human neurogenesis and observed protein-coding neighborhoods to be disproportionately conserved between humans and other large-brained mammalian species (Figures 6A,B). In fact, whether or not a species showed greater-than-expected conservation could be better predicted by brain weight than body weight, maximum lifespan, or even gestation period (Figure 6C). The conservation of such regions over tens of millions of years, as well as the relatively recent loss of 

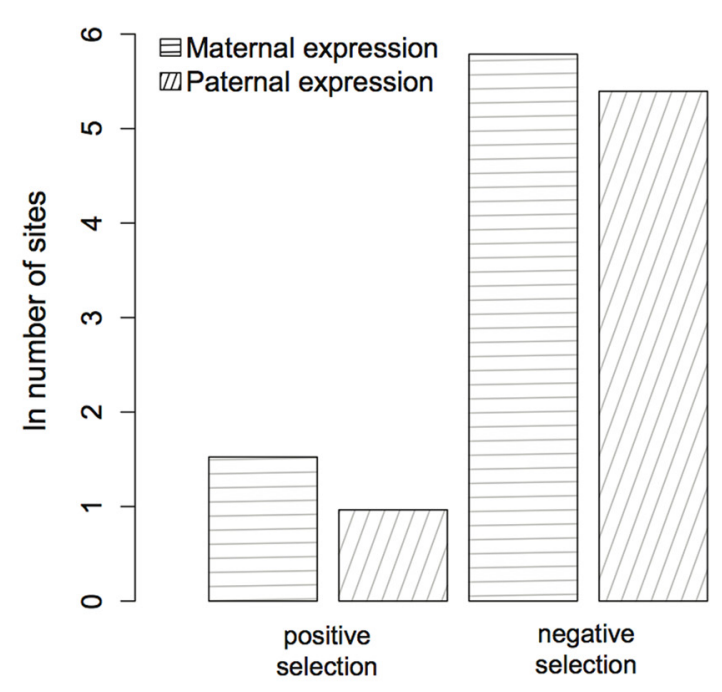
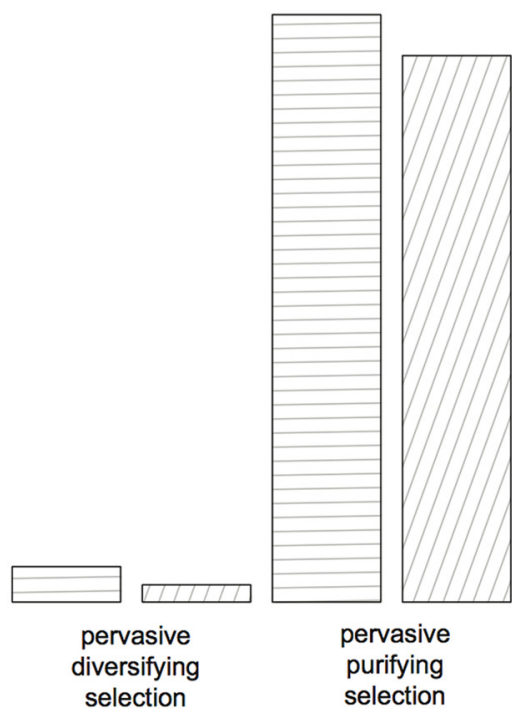

FIGURE 4 | Evidence for selection in 51 maternally (horizontal lines) and paternally (oblique lines) expressed genes (see Table A1). The parent-of-origin of the expressed allele has no significant affect $(P \geq 0.07)$ on the number of selected sites.

the same regions in small-brained species, indicates an important role for lincRNA in the differential regulation, and especially timing, of neurodevelopment in large- vs. small-brained species. Heterochrony has been suggested as an expedient for brain evolution (Kelava et al., 2011) and lincRNAs may be one mechanism for achieving such changes in neurodevelopmental timing. We may point to the lincRNA located on chromosome 15q11-q13 as an example of a neurogenic regulator overrepresented in large-brained species and propose more generally that lengthening or shortening of the period of in utero maternal investment requires, at least where neurodevelopment is concerned, the conservation or loss, respectively, of cis-regulatory genomic regions.

\section{PARENT-OFFSPRING CONFLICT AND PARENTAL-BIASED SELECTION ON NEOCORTICAL EXPANSION}

According to Hamilton's Kin Selection Theory (Hamilton, 1964a,b), the transfer of nutrients from mother to fetus may be viewed as evidence of altruism, because increased maternal investment reduces the fitness of the mother while increasing the fitness of the fetus. But this is not strictly the case. Early in development, fetal trophoblast cells invade the maternal endometrium and remodel the maternal vasculature (Angiolini et al., 2006), effectively wresting control of maternal-to-fetal blood flow from the mother. In polyandrous societies, which dominate in mammals, the fetus may be seen as a proxy for the father, his lone representative, due to the fact that the paternal genome will only pass through the patriline. So in order to optimize the fitness of patrilineal progeny, paternally inherited alleles favor increased maternal investment (i.e., promote growth) compared to maternally inherited alleles; and the allocation of maternal resources to the fetus, therefore, is less an altruistic arrangement between mother and fetus-except perhaps where hemostatic regulation is concerned-but an intragenomic conflict between paternal and maternal interests (Moore and Haig, 1991; Haig, 2010). The incremental evolution of imprinted domains and increased risk of neurodevelopmental disease associated with parent-oforigin-linked gene expression suggest, firstly, that this conflict is not brokered exclusively in growth hormones at the fetalplacental interface and, secondly, that both parents evolve selfish strategies that lead to higher risk of disease for the population at large, reminiscent of Hardin's "tragedy of the commons" (Hardin, 1968), in the evolutionary arms race to regulate fetal development.

\section{INCREMENTAL EVOLUTION OF IMPRINTED DOMAINS AND ITS NEURODEVELOPMENTAL EFFECTS}

Imprinted regions manifest as the epigenetic silencing of one allele and high expression of the other. It is unlikely that the levels of expression observed in imprinted regions evolved suddenly, but that the large detectable differences in parental allelic expression are the consequence of a gradual gene-expression arms race (Mills and Moore, 2006; Moore, 2012). Indeed, many genes show expression bias for one allele, but not complete silencing of the other allele (Gregg, 2010). Following many generations of selection for increased expression at each parental site, the difference between the alleles may be nearly unchanged, but the absolute level of expression at each allele will have increased dramatically, thereby ministering a more striking maternal- or paternal-biased phenotype when the opposite allele is imprinted. Because evolutionary models of brain-specific imprinted genomic regions have been limited (O'Connell et al., 2010; McCole et al., 2011), it is difficult to surmise whether a maternal- or paternal-biased phenotype has been under selection or even what that phenotype may be. While experimental evidence for the phenotypic effects of imprinted domains has been conducted in the mouse, our hypothesis predicts these effects will be contrapositive to those present in the human and other large-brained 


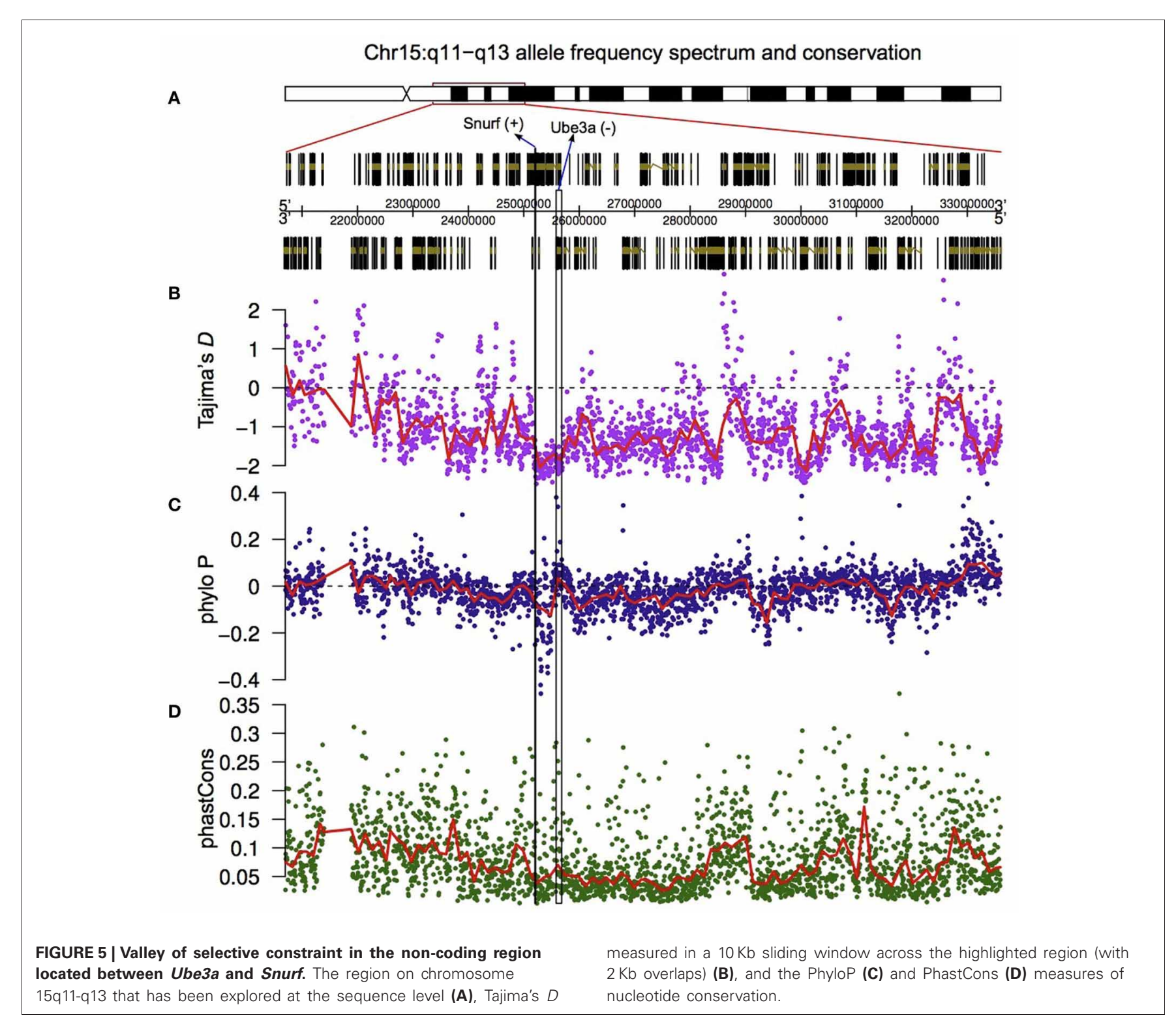

Table 1 | McDonald-Kreitman test for adaptive evolution of non-coding RNAs on human chromosome 15q11-q13.

\begin{tabular}{lccr}
\hline & Polymorphic & Divergent & Total \\
\hline Neutral & 56 & 24.07 & 80.07 \\
Selected & 102 & 186.25 & 288.25 \\
Total & 158 & 210.32 & 368.32 \\
\hline
\end{tabular}

A $2 \times 2$ contingency table showing the numbers of polymorphic and divergent bases (relative to the chimpanzee) for three lincRNAs (Selected) bounded by Snurf and Ube3a, and for the silent sites in the coding regions of Snurf, Ube3a, and Atp10a (Neutral). The test shows that there is a significant excess of adaptive substitutions in the lincRNAs $\left(P=6.72 \times 10^{-8}\right.$, chi-squared test $)$.

species. A three-fold increase in human compared to mouse imprinted genes expressed during cortical neurogenesis supports this claim (see Figure 1). Therefore, any phenotypic evidence presented for the disruption or manipulation of imprinted domains in the mouse cannot, we contend, be extrapolated to the human. As a first step in investigating a mammalian-wide evolutionary picture of parent-of-origin-linked genes, we present evidence that imprinted genomic regions have been under pervasive purifying selection, indicative of both the role of these genes in disease (Blekhman et al., 2008; Cai et al., 2009) and the importance of non-coding neighbors in their temporal-, tissue-, and species-specific regulation of expression. The phenotypic effects of an evolutionary arms race between maternal and paternal alleles in humans is further evident in the numerous pathologies that present themselves when parent-oforigin-linked gene expression is imbalanced during neurodevelopment. Finally, the large metabolic costs of neurodevelopment during gestation advance the brain as a likely target for intragenomic conflict over resource allocation, even if pathways of maternal-fetal metabolic regulation are not directly the subjects of selection. 

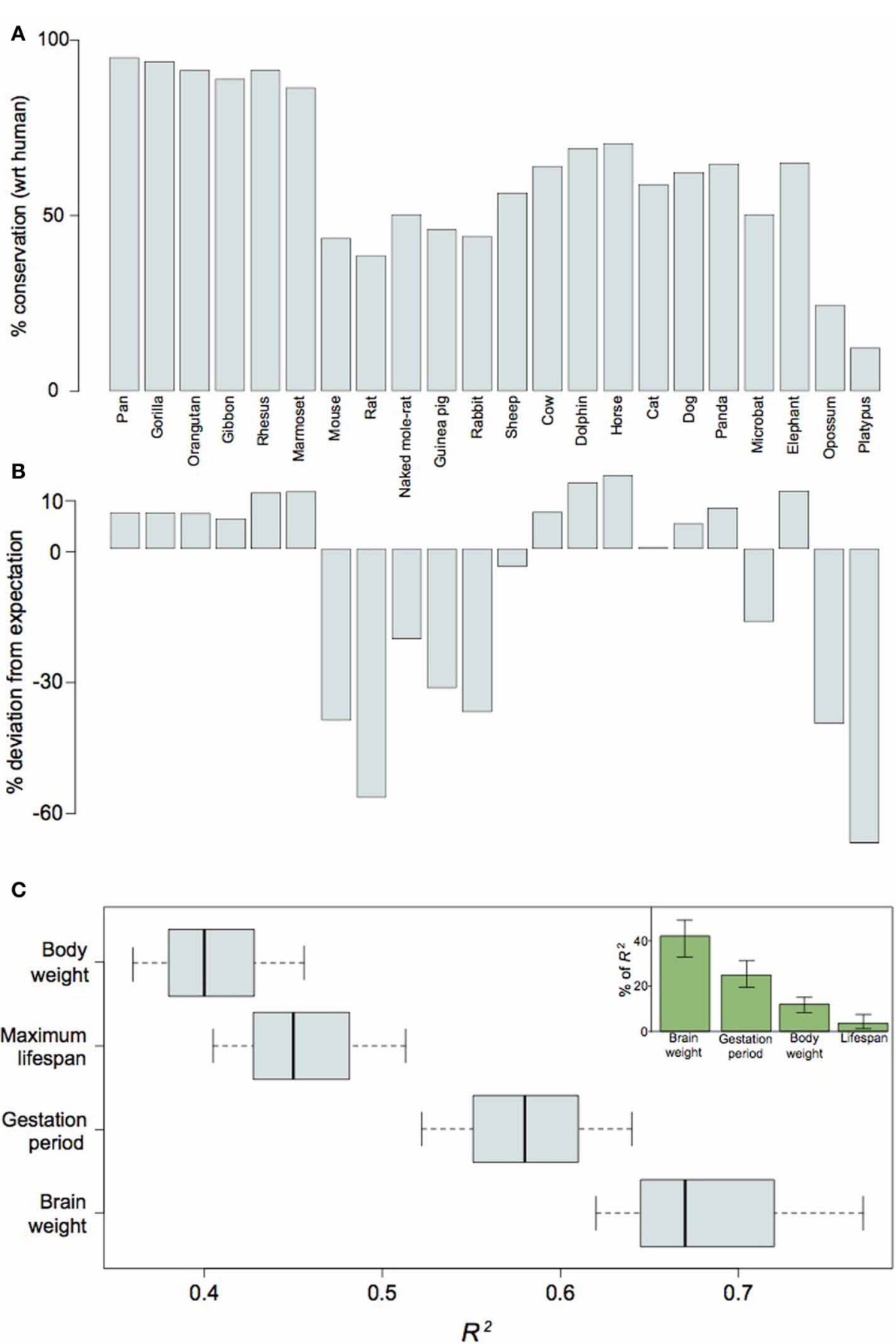

FIGURE 6 | LincRNA differentially expressed in human neocortical germinal zones are conserved with respect to their proximity to flanking genes between human and other large-brained mammalian species. Barplots of absolute contextual conservation (A) and percent deviation of conservation from expectations-based on phylogenetic distance (B) for 161 lincRNA in 22 mammal species; Pearson's $R^{2}$ scores for values in (B) as functions of brain weight, body weight, maximum lifespan, and gestation period (C). The inset in (C) shows the relative contributions of each variable as a function of the total power of the combined variables $\left(R^{2}=82.5\right)$ for explaining values in (B). Note that values in (B) may be better explained by brain weight than any other variable $(P<0.1$, Welch's $t$-test $)$

\section{NEOCORTICAL EXPANSION: TRAGEDY OF THE COMMONS}

Monoallelic gene expression increases the risk of disease, because the functional haploidy associated with genomic imprinting increases the chances of an individual experiencing the phenotypic effects of a recessive deleterious mutation. While these mutations may have little-to-no effect when heterozygous at an unimprinted locus, they present severe fitness effects at an imprinted locus, where the functional haploidy associated 
with imprinting gives a recessive deleterious mutation a $50 \%$ chance of presenting itself. This introduces a scenario in which both parents have evolved a system in which, if either parent's gene is not sufficiently expressed and its phenotype successfully passed through its respective lineage, then the fetus will suffer (often lethal) developmental defects. This is an evolutionary Tragedy of the Commons because ever-more selfish strategies will inevitably evolve at the expense of the fitness of the whole population.

So why would genomic imprinting have evolved an important role in mammalian brain development and why should we expect selection in genomically imprinted domains? The evidence presented here for pervasive purifying selection on imprinted neurogenic genes suggests that parent-offspring conflict has affected these genes by acting selectively on non-coding regulators of their expression, thus influencing their expression without affecting their overall function. Indeed, our analysis of the non-coding domain on chromosome 15q11-q13 and, more broadly, our observation that putatively cis-acting lincRNAs are selectively conserved in large-brained mammalian species predict a requisite role for non-coding regions in evolving and developing a large brain. Of course, the general positive correlation of lincRNA conservation with not only brain weight, but also body weight, lifespan, and gestation period (see Figure 6C) may suggest that lincRNAs are selectively lost along lineages leading to smaller species with shorter life-histories, evincing a broad mechanistic role for lincRNAs in facilitating evolutionary

\section{REFERENCES}

Abitbol, M., Menini, C., Delezoide, A. L., Rhyner, T., Vekemans, M., and Mallet, J. (1993). Nucleus basalis magnocellularis and hippocampus are the major sites of FMR-1 expression in the human fetal brain. Nat. Genet. 4, 147-153.

Albrecht, U., Sutcliffe, J. S., Cattanach, B. M., Beechey, C. V., Armstrong, D., Eichele, G., et al. (1997). Imprinted expression of the murine Angelman syndrome gene, Ube3a, in hippocampal and Purkinje neurons. Nat. Genet. 17, 75-78.

Anders, S., and Huber, W. (2010). Differential expression analysis for sequence count data. Genome Biol. 11:R106. doi: 10.1186/gb-2010-1110-r106

Angiolini, E., Fowden, A., Coan, P., Sandovici, I., Smith, P., Dean, W., et al. (2006). Regulation of placental efficiency for nutrient transport by imprinted genes. Placenta 27(Suppl. A), S98-S102.

Anisimova, M., and Kosiol, C. (2009). Investigating protein-coding sequence evolution with probabilistic codon substitution models. Mol. Biol. Evol. 26, 255-271.

Anisimova, M., and Yang, Z. (2007). Multiple hypothesis testing to detect lineages under positive selection that affects only a few sites. Mol. Biol. Evol. 24, 1219-1228.

Arngrímsson, R. (2005). Epigenetics of hypertension in pregnancy. Nat. Genet. 37, 460-461.

Bartolomei, M. S., and FergusonSmith, A. C. (2011). Mammalian genomic imprinting. Cold Spring Harb. Perspect. Biol. 3:a002592. doi: 10.1101/cshperspect.a002592

Bhattacharyya, A., McMillan, E., Wallace, K., Tubon, T. C. Jr., Capowski, E. E., and Svendsen, C. N. (2008). Normal neurogenesis but abnormal gene expression in human Fragile $\mathrm{X}$ cortical progenitor cells. Stem Cells Dev. 17, 107-117.

Blekhman, R., Man, O., Herrmann, L., Boyko, A. R., Indap, A., Kosiol, C., et al. (2008). Natural selection on genes that underlie human disease susceptibility. Curr. Biol. 18, 883-889.

Brannan, C. I., and Bartolomei, M. S. (1999). Mechanisms of genomic imprinting. Curr. Opin. Genet. Dev. 9, 164-170.

Butti, C., Raghanti, M. A., Sherwood, C. C., and Hof, P. R. (2011). The neocortex of cetaceans: cytoarchitecture and comparison with other aquatic and terrestrial species. Ann. N.Y. Acad. Sci. 1225, 47-58.

changes to developmental timing and, more generally, underscoring the constraining role of the rate of meiotic recombination in the evolutionary history of a species (Romiguier et al., 2013). But even though a higher rate of meiosis may increase the frequency of meiotic errors and therefore the likelihood of losing lincRNAs in small species, the small effective population size of most large species would also hasten the loss of weakly selected genomic regions. As such, the conservation of lincRNAs along any lineage should be evidence of strong selection and function.

Because workers have shown that positively selected genes affecting human-specific phenotypes are more likely to be expressed in fetal compared to adult tissue (Uddin et al., 2008), it follows that genomically imprinted domains should show signatures of selection along mammalian lineages with ostensible evidence for maternal- or paternal-biased phenotypes. We posit that the mammalian, and especially human, neocortex presents such a phenotype; and that further computational and experimental studies on imprinted domains will help us understand how parent-offspring conflict has influenced maternal- or paternalbiased brain phenotypes at the genomic level.

\section{ACKNOWLEDGMENTS}

Eric Lewitus was supported by the Max Planck Society. Alex T. Kalinka was supported by an HFSP Young Investigator grant RGY0084. Eric Lewitus would like to thank Evan Charles for helpful discussion.

Cabili, M. N., Trapnell, C., Goff, L., Koziol, M., Tazon-Vega, B., Regev, A., et al. (2011). Integrative annotation of human large intergenic noncoding RNAs reveals global properties and specific subclasses. Genes Dev. 25, 1915-1927.

Cai, J. J., Borenstein, E., Chen, R., and Petrov, D. A. (2009). Similarly strong purifying selection acts on human disease genes of all evolutionary ages. Genome Biol. Evol. 1, 131-144.

Callan, M. A., and Zarnescu, D. C. (2011). Heads-up: new roles for the Fragile X mental retardation protein in neural stem and progenitor cells. Genesis 49, 424-440.

Cassidy, S. B., and Driscoll, D. J. (2009). Prader-Willi syndrome. Eur. J. Hum. Genet. 17, 3-13.

Castrén, M., Tervonen, T., Kärkkäinen, V., Heinonen, S., Castrén, E., Larsson, K., et al. (2005). Altered differentiation of neural stem cells in Fragile X syndrome. Proc. Natl. Acad. Sci. U.S.A. 102, 17834-17839.

Chamberlain, S. J., and Lalande, M. (2010). Neurodevelopmental disorders involving genomic imprinting at human chromosome 15q11-q13. Neurobiol. Dis. 39, 13-20.

Constância, M., Kelsey, G., and Reik, W. (2004). Resourceful imprinting. $\quad$ Nature 432, 53-57.

Crespi, B. (2008). Genomic imprinting in the development and evolution of psychotic spectrum conditions. Biol. Rev. Camb. Philos. Soc. 83, 441-493.

Curley, J. P., Barton, S., Surani, A., and Keverne, E. B. (2004). Coadaptation in mother and infant regulated by a paternally expressed imprinted gene. Proc. Biol. Sci. 271, 1303-1309.

Davies, W., Isles, A. R., Burgoyne, P. S., and Wilkinson, L. S. (2006). Xlinked imprinting: effects on brain and behaviour. Bioessays 28, 35-44.

Delport, W., Poon, A. F. Y., Frost, S. D. W., and Kosakovsky Pond, S. L. (2010a). Datamonkey 2010: a suite of phylogenetic analysis tools for evolutionary biology. Bioinformatics 26, 2455-2457.

Delport, W., Scheffler, K., Botha, G., Gravenor, M. B., Muse, S. V., and Kosakovsky Pond, S. L. (2010b). CodonTest: modeling amino acid substitution preferences in coding sequences. PLoS Comput. Biol. 6:e1000885. doi: 10.1371/journal.pcbi.1000885

Devys, D., Lutz, Y., Rouyer, N., Bellocq, J. P., and Mandel, J. L. (1993). The FMR-1 protein is cytoplasmic, most abundant in neurons and appears 
normal in carriers of a Fragile $\mathrm{X}$ premutation. Nat. Genet. 4, 335-340.

Dindot, S. V., Antalffy, B. A., Bhattacharjee, M. B., and Beaudet, A. L. (2008). The Angelman syndrome ubiquitin ligase localizes to the synapse and nucleus, and maternal deficiency results in abnormal dendritic spine morphology. Hum. Mol. Genet. 17, 111-118.

Eliez, S., Blasey, C. M., Freund, L. S., Hastie, T., and Reiss, A. L. (2001). Brain anatomy, gender and IQ in children and adolescents with Fragile X syndrome. Brain 124, 1610-1618.

Fitzpatrick, G. V., Soloway, P. D., and Higgins, M. J. (2002). Regional loss of imprinting and growth deficiency in mice with a targeted deletion of KvDMR1. Nat. Genet. 32, 426-431.

Franco, S. J., and Müller, U. (2013). Shaping our minds: stem and progenitor cell diversity in the mammalian neocortex. Neuron 77, 19-34.

Frank, M., and Kemler, R. (2002). Protocadherins. Curr. Opin. Cell Biol. 14, 557-562.

Fu, Y. H., Kuhl, D. P., Pizzuti, A., Pieretti, M., Sutcliffe, J. S., Richards, S., et al. (1991). Variation of the CGG repeat at the Fragile $\mathrm{X}$ site results in genetic instability: resolution of the Sherman paradox. Cell 67, 1047-1058.

Gregg, C. (2010). Eppendorf winner. Parental control over the brain. Science 330, 770-771.

Hager, R., Lu, L., Rosen, G. D., and Williams, R. W. (2012). Genetic architecture supports mosaic brain evolution and independent brainbody size regulation. Nat. Commun. 3:1079. doi: $10.1038 /$ ncomms2086

Haig, D. (1993). Genetic conflicts in human pregnancy. Q. Rev. Biol. 68, 495-532.

Haig, D. (2010). Colloquium papers: transfers and transitions: parentoffspring conflict, genomic imprinting, and the evolution of human life history. Proc. Natl. Acad. Sci. U.S.A. 107(Suppl. 1), 1731-1735.

Hamilton, W. D. (1964a). The genetical evolution of social behaviour. I. J. Theor. Biol. 7, 1-16.

Hamilton, W. D. (1964b). The genetical evolution of social behaviour. II. J. Theor. Biol. 7, 17-52.

Hardin, G. (1968). The tragedy of the commons. Science 162, 1243-1248.

Harvey, P. H., and Krebs, J. (1990). Comparing brains. Science 249, 140-146.

Hazlett, H. C., Poe, M. D., Lightbody, A. A., Gerig, G., Macfall, J. R., Ross, A. K., et al. (2009). Teasing apart the heterogeneity of autism: same behavior, different brains in toddlers with Fragile $\mathrm{X}$ syndrome and autism. J. Neurodev. Disord. 1, 81-90.

Hinds, H. L., Ashley, C. T., Sutcliffe, J. S., Nelson, D. L., Warren, S. T., Housman, D. E., et al. (1993). Tissue specific expression of FMR-1 provides evidence for a functional role in Fragile X syndrome. Nat. Genet. 3, 36-43.

Hoeft, F., Lightbody, A. A., Hazlett, H. C., Patnaik, S., Piven, J., and Reiss, A. L. (2008). Morphometric spatial patterns differentiating boys with Fragile X syndrome, typically developing boys, and developmentally delayed boys aged 1 to 3 years. Arch. Gen. Psychiatry 65, 1087-1097.

Jukes, T. H., and Cantor, C. R. (1969). Evolution of Protein Molecules. New York, NY: Academic Press. 21-132.

Kelava, I., Reillo, I., Murayama, A. Y., Kalinka, A. T., Stenzel, D., Tomancak, P., et al. (2011). Abundant occurrence of basal radial glia in the subventricular zone of embryonic neocortex of a lissencephalic primate, the common marmoset callithrix jacchus. Cereb. Cortex 22, 469-481.

Keverne, E. B., Fundele, R., Narasimha, M., Barton, S. C., and Surani, M. A. (1996). Genomic imprinting and the differential roles of parental genomes in brain development. Brain Res. Dev. Brain Res. 92, 91-100.

Killian, J. K., Nolan, C. M., Stewart, N., Munday, B. L., Andersen, N. A., Nicol, S., et al. (2001a). Monotreme IGF2 expression and ancestral origin of genomic imprinting. J. Exp. Zool. 291, 205-212.

Killian, J. K., Nolan, C. M., Wylie, A. A., Li, T., Vu, T. H., Hoffman, A. R., et al. (2001b). Divergent evolution in M6P/IGF2R imprinting from the jurassic to the quaternary. Hum. Mol. Genet. 10, 1721-1728.

Kishino, T., Lalande, M., and Wagstaff, J. (1997). UBE3A/E6-AP mutations cause Angelman syndrome. Nat. Genet. 15, 70-73.

Kosakovsky Pond, S. L. (2005). Not so different after all: a comparison of methods for detecting amino acid sites under selection. Mol. Biol. Evol. 22, 1208-1222.

Kosakovsky Pond, S. L., Murrell, B., Fourment, M., Frost, S. D. W., Delport, W., and Scheffler, K. (2011). A random effects branchsite model for detecting episodic diversifying selection. Mol. Biol. Evol. 28, 3033-3043.

Kumar, S., Talis, A. L., and Howley, P. M. (1999). Identification of
HHR23A as a substrate for E6-associated protein-mediated ubiquitination. J. Biol. Chem. 274, 18785-18792.

Kumari, D., and Usdin, K. (2001) Interaction of the transcription factors USF1, USF2, and alpha $\mathrm{Pal} / \mathrm{Nrf}-1$ with the FMR1 promoter. Implications for Fragile $\mathrm{X}$ mental retardation syndrome. J. Biol. Chem. 276, 4357-4364.

Landers, M., Bancescu, D. L., Le Meur E., Rougeulle, C., Glatt-Deeley, H., Brannan, C., et al. (2004). Regulation of the large $(\sim 1000 \mathrm{~kb})$ imprinted murine Ube3a antisense transcript by alternative exons upstream of Snurf/Snrpn. Nucleic Acids Res. 32, 3480-3492.

Lawton, B. R., Sevigny, L., Obergfell, C., Reznick, D., O’Neill, R. J., and O'Neill, M. J. (2005). Allelic expression of IGF2 in live-bearing, matrotrophic fishes. Dev. Genes Evol. 215, 207-212.

Laxova, R. (1994). Fragile X syndrome. Adv. Pediatr. 41, 305-342.

Lee, A. D., Leow, A. D., Lu, A., Reiss, A. L., Hall, S., Chiang, M.-C., et al. (2007). 3D pattern of brain abnormalities in Fragile $\mathrm{X}$ syndrome visualized using tensor-based morphometry. Neuroimage 34, 924-938.

Lewis, A., and Reik, W. (2006). How imprinting centres work. Cytogenet. Genome Res. 113, 81-89.

Lewitus, E., Hof, P. R., and Sherwood, C. C. (2012a). Phylogenetic comparison of neuron and glia densities in the primary visual cortex and hippocampus of carnivores and primates. Evolution 66, 2551-2563.

Lewitus, E., Sherwood, C. C., and Hof, P. R. (2012b). Cellular signatures in the primary visual cortex of phylogeny and placentation. Brain Struct. Funct. 217, 531-547.

Li, L., Keverne, E. B., Aparicio, S. A., Ishino, F., Barton, S. C., and Surani, M. A. (1999). Regulation of maternal behavior and offspring growth by paternally expressed Peg3. Science 284, 330-333.

Lin, S.-P., Youngson, N., Takada, S., Seitz, H., Reik, W., Paulsen, M., et al. (2003). Asymmetric regulation of imprinting on the maternal and paternal chromosomes at the Dlk1-Gtl2 imprinted cluster on mouse chromosome 12. Nat. Genet. $35,97-102$.

Mancini-Dinardo, D., Steele, S. J. S., Levorse, J. M., Ingram, R. S., and Tilghman, S. M. (2006). Elongation of the Kcnqlotl transcript is required for genomic imprinting of neighboring genes. Genes Dev. 20, 1268-1282.
McCole, R. B., Loughran, N. B., Chahal, M., Fernandes, L. P., Roberts, R. G., Fraternali, F., et al. (2011). A caseby-case evolutionary analysis of four imprinted retrogenes. Evolution 65, 1413-1427.

McDonald, J. H., and Kreitman, M. (1991). Adaptive protein evolution at the Adh locus in Drosophila. Nature 351, 652-654.

McNab, B. (1989). Brain size and its relation to the rate of metabolism in mammals. Am. Nat. 133, 157-167.

Meredith, R. W., Janeěka, J. E., Gatesy, J., Ryder, O. A., Fisher, C. A., Teeling, E. C., et al. (2011). Impacts of the cretaceous terrestrial revolution and KPg extinction on mammal diversification. Science 334 521-524.

Le Meur, E., Watrin, F., Landers, M., Sturny, R., Lalande, M., and Muscatelli, F. (2005). Dynamic developmental regulation of the large non-coding RNA associated with the mouse 7C imprinted chromosomal region. Dev. Biol. 286, 587-600.

Mills, W., and Moore, T. (2006). Evolution of mammalian $\mathrm{X}$ chromosome-linked imprinting. Cytogenet. Genome Res. 113, 336-344.

Moore, T. (2012). Review: parentoffspring conflict and the control of placental function. Placenta 33(Suppl.), S33-S36.

Moore, T., and Haig, D. (1991). Genomic imprinting in mammalian development: a parental tug-of-war. Trends Genet. 7, 45-49.

Mostofsky, S. H., Mazzocco, M. M., Aakalu, G., Warsofsky, I. S., Denckla, M. B., Reiss, A. L., et al. (1995). Neurodevelopmental effects of the FMR-1 full mutation in humans. Nat. Med. 1, 159-167.

Nguyen, D. K., and Disteche, C. M. (2006). High expression of the mammalian $\mathrm{X}$ chromosome in brain. Brain Res. 1126, 46-49.

Oberle, I., Rousseau, F., Heitz, D., Kretz, C., Devys, D., Hanauer, A., et al. (1991). Instability of a 550-base pair DNA segment and abnormal methylation in fragile $\mathrm{X}$ syndrome. Science 252, 1097-1102.

O'Connell, M. J., Loughran, N. B., Walsh, T. A., Donoghue, M. T. A., Schmid, K. J., and Spillane, C. (2010). A phylogenetic approach to test for evidence of parental conflict or gene duplications associated with protein-encoding imprinted orthologous genes in placental mammals. Mamm. Genome 21, 486-498.

Ørom, U. A., and Shiekhattar, R. (2011). Long non-coding RNAs and 
enhancers. Curr. Opin. Genet. Dev. 21, 194-198.

Oudejans, C. B. M., Mulders, J., Lachmeijer, A. M. A., van Dijk, M., Könst, A. A. M., Westerman, B. A., et al. (2004). The parentof-origin effect of 10q22 in pre-eclamptic females coincides with two regions clustered for genes with down-regulated expression in androgenetic placentas. Mol. Hum. Reprod. 10, 589-598.

Penagarikano, O., Mulle, J. G., and Warren, S. T. (2007). The pathophysiology of fragile $\mathrm{x}$ syndrome. Annu. Rev. Genomics Hum. Genet. 8, 109-129.

Rapkins, R. W., Hore, T., Smithwick, M., Ager, E., Pask, A. J., Renfree, M. B., et al. (2006). Recent assembly of an imprinted domain from non-imprinted components. PLoS Genet. 2:e182. doi: 10.1371/journal.pgen.0020182

Reik, W., Santos, F., Mitsuya, K., Morgan, H., and Dean, W. (2003). Epigenetic asymmetry in the mammalian zygote and early embryo: relationship to lineage commitment? Philos. Trans. R. Soc. Lond. B Biol. Sci. 358, 1403-1409. discussion: 1409.

Reik, W., and Walter, J. (2001). Genomic imprinting: parental influence on the genome. Nat. Rev. Genet. 2, 21-32.

Reis, A., Dittrich, B., Greger, V., Buiting, K., Lalande, M., GillessenKaesbach, G., et al. (1994). Imprinting mutations suggested by abnormal DNA methylation patterns in familial Angelman and Prader-Willi syndromes. Am. J. Hum. Genet. 54, 741-747.

Reiss, A. L., Mazzocco, M. M., Greenlaw, R., Freund, L. S., and Ross, J. L. (1995). Neurodevelopmental effects of $\mathrm{X}$ monosomy: a volumetric imaging study. Ann. Neurol. 38, 731-738.

Renfree, M. B., Hore, T. A., Shaw, G., Graves, J. A. M., and Pask, A. J. (2009). Evolution of genomic imprinting: insights from marsupials and monotremes. Annu. Rev. Genomics Hum. Genet. 10, 241-262.

Romiguier, J., Ranwez, V., Douzery, E. J. P., and Galtier, N. (2013). Genomic evidence for large, long-lived ancestors to placental mammals. Mol. Biol. Evol. 30, 5-13.

Rougeulle, C., Cardoso, C., Fontés, M., Colleaux, L., and Lalande,
M. (1998). An imprinted antisense RNA overlaps UBE3A and a second maternally expressed transcript. Nat. Genet. 19, 15-16.

Runte, M., Hüttenhofer, A., Gross, S., Kiefmann, M., Horsthemke, B., and Buiting, K. (2001). The IC-SNURFSNRPN transcript serves as a host for multiple small nucleolar RNA species and as an antisense RNA for UBE3A. Hum. Mol. Genet. 10, 2687-2700.

Saffary, R., and Xie, Z. (2011). FMRP regulates the transition from radial glial cells to intermediate progenitor cells during neocortical development. J. Neurosci. 31, 1427-1439.

Saitoh, S., Buiting, K., Rogan, P. K., Buxton, J. L., Driscoll, D. J., Arnemann, J., et al. (1996). Minimal definition of the imprinting center and fixation of chromosome 15q11-q13 epigenotype by imprinting mutations. Proc. Natl. Acad. Sci. U.S.A. 93, 7811-7815.

Santoro, F., and Barlow, D. P. (2011). Developmental control of imprinted expression by macro non-coding RNAs. Semin. Cell Dev. Biol. 22, 328-335.

Singhmar, P., and Kumar, A. (2011). Angelman syndrome protein UBE3A interacts with primary microcephaly protein ASPM, localizes to centrosomes and regulates chromosome segregation. PLoS ONE 6:e20397. doi: 10.1371/journal.pone.0020397

Skuse, D. H., James, R. S., Bishop, D. V., Coppin, B., Dalton, P., AamodtLeeper, G., et al. (1997). Evidence from Turner's syndrome of an imprinted X-linked locus affecting cognitive function. Nature 387, 705-708.

Sleutels, F., and Barlow, D. P. (2002). The origins of genomic imprinting in mammals. Adv. Genet. 46, 119-163.

Smith, N. G., and Eyre-Walker, A. (2002). Adaptive protein evolution in Drosophila. Nature 415, 1022-1024.

Srivenugopal, K. S., and Ali-Osman, F. (2002). The DNA repair protein, $\mathrm{O}(6)$-methylguanine-DNA methyltransferase is a proteolytic target for the E6 human papillomavirus oncoprotein. Oncogene 21, 5940-5945.

Swingland, J. T., Durrenberger, P. F., Reynolds, R., Dexter, D. T., Pombo, A., Deprez, M., et al. (2012). Mean expression of the X-Chromosome is associated with neuronal density. Front. Neurosci. 6:161. doi 10.3389/fnins.2012.00161

Tajima, F. (1989). Statistical method for testing the neutral mutation hypothesis by DNA polymorphism. Genetics 123, 585-595.

Tervonen, T. A., Louhivuori, V., Sun, X. Hokkanen, M.-E., Kratochwil, C. F., Zebryk, P., et al. (2009). Aberrant differentiation of glutamatergic cells in neocortex of mouse model for fragile X syndrome. Neurobiol. Dis. 33, 250-259.

The 1000 Genomes Project Consortium, (2011). A map of human genome variation from population-scale sequencing Nature 467, 1061-1073.

Thorvaldsen, J. L., Duran, K. L., and Bartolomei, M. S. (1998). Deletion of the H19 differentially methylated domain results in loss of imprinted expression of H19 and Igf2. Genes Dev. 12, 3693-3702.

Trivers, R. L. (1974). Parent-offspring conflict. Integr. Comp. Biol. 14, 249-264.

Tycko, B., and Morison, I. M. (2002). Physiological functions of imprinted genes. J. Cell. Physiol. 192, 245-258.

Ubeda, F., and Wilkins, J. F. (2008) Imprinted genes and human disease: an evolutionary perspective. Adv. Exp. Med. Biol. 626, 101-115.

Uddin, M., Goodman, M., Erez, O., Romero, R., Liu, G., Islam, M., et al. (2008). Distinct genomic signatures of adaptation in pre- and postnatal environments during human evolution. Proc. Natl. Acad. Sci. U.S.A. 105, 3215-3220.

van Dijk, M., Mulders, J., Poutsma, A., Könst, A. A. M., Lachmeijer, A. M. A., Dekker, G. A., et al. (2005). Maternal segregation of the Dutch preeclampsia locus at $10 \mathrm{q} 22$ with a new member of the winged helix gene family. Nat. Genet. 37, 514-519.

Verkerk, A. J., Pieretti, M., Sutcliffe, J. S., Fu, Y. H., Kuhl, D. P., Pizzuti, A. et al. (1991). Identification of a gene (FMR-1) containing a CGG repeat coincident with a breakpoint cluster region exhibiting length variation in fragile X syndrome. Cell 65 , 905-914.

Wilkins, J. F., and Haig, D. (2003). What good is genomic imprinting: the function of parent-specific gene expression. Nat. Rev. Genet. 4, 359-368.

Wilkinson, L. S., Davies, W., and Isles, A. R. (2007). Genomic imprinting effects on brain development and function. Nat. Rev. Neurosci. 8, 832-843.

Williamson, C. M., Turner, M. D., Ball, S. T., Nottingham, W. T. Glenister, P., Fray, M., et al. (2006). Identification of an imprinting control region affecting the expression of all transcripts in the Gnas cluster. Nat. Genet. 38, 350-355.

Wolf, J. B., and Hager, R. (2006). A maternal-offspring coadaptation theory for the evolution of genomic imprinting. PLoS Biol. 4:e380. doi: 10.1371/journal.pbio.0040380

Wutz, A., Smrzka, O. W., Schweifer, N., Schellander, K., Wagner, E. F., and Barlow, D. P. (1997). Imprinted expression of the Igf2r gene depends on an intronic CpG island. Nature 389, 745-749.

Yamasaki, K., Joh, K., Ohta, T., Masuzaki, H., Ishimaru, T., Mukai, T., et al. (2003). Neurons but not glial cells show reciprocal imprinting of sense and antisense transcripts of Ube3a. Hum. Mol. Genet. 12, 837-847.

Yang, Z., and dos Reis, M. (2011). Statistical properties of the branchsite test of positive selection. Mol. Biol. Evol. 28, 1217-1228.

Conflict of Interest Statement: The authors declare that the research was conducted in the absence of any commercial or financial relationships that could be construed as a potential conflict of interest.

Received: 04 February 2013; paper pending published: 05 March 2013; accepted: 18 March 2013; published online: 09 April 2013

Citation: Lewitus $E$ and Kalinka AT (2013) Neocortical development as an evolutionary platform for intragenomic conflict. Front. Neuroanat. 7:2. doi: 10.3389/fnana.2013.00002

Copyright (c) 2013 Lewitus and Kalinka. This is an open-access article distributed under the terms of the Creative Commons Attribution License, which permits use, distribution and reproduction in other forums, provided the original authors and source are credited and subject to any copyright notices concerning any third-party graphics etc. 


\section{APPENDIX}

Table A1 | Selection statistics for imprinted neurogenic genes in human and mouse.

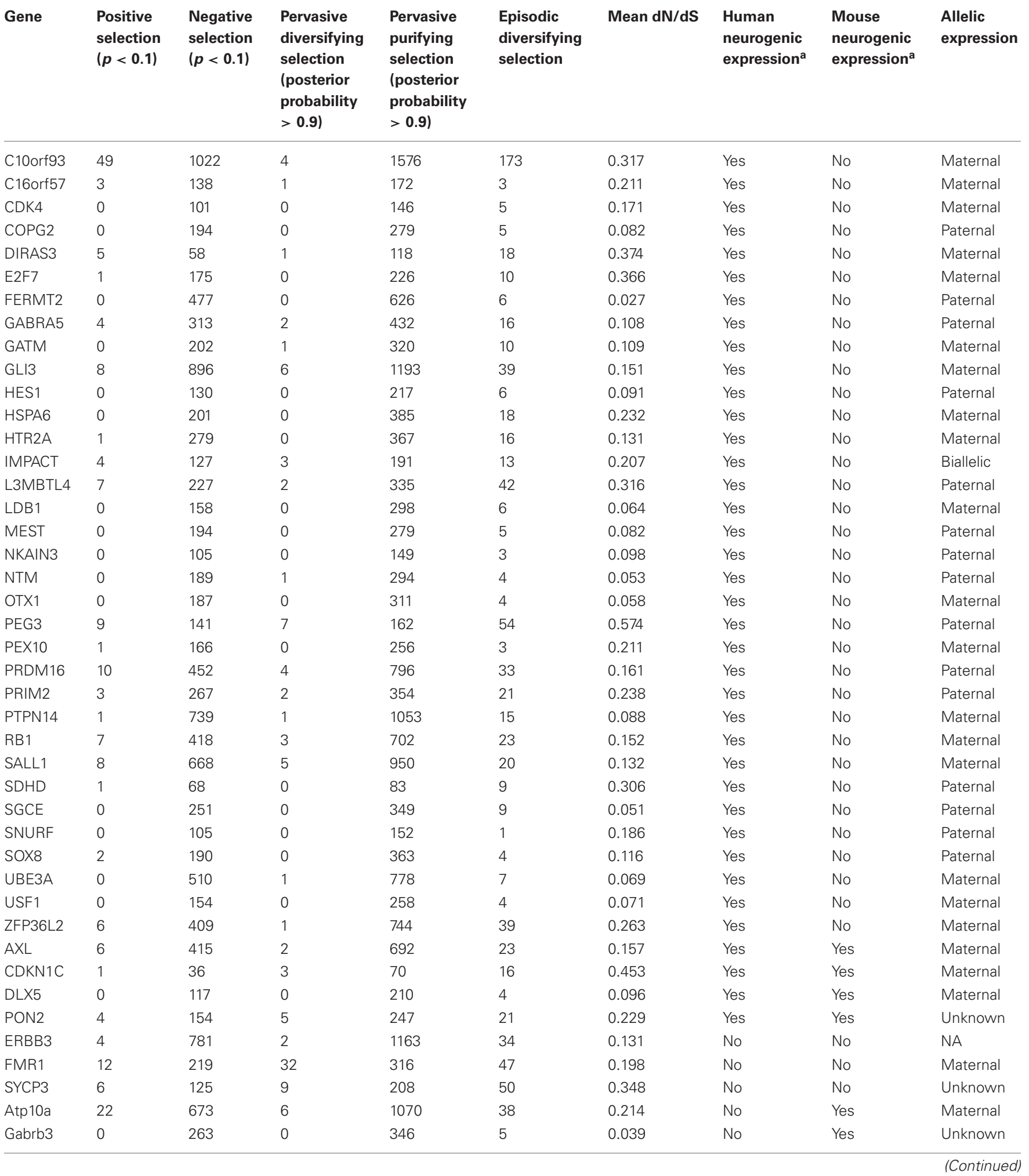


Table A1 | Continued

\begin{tabular}{|c|c|c|c|c|c|c|c|c|c|}
\hline Gene & $\begin{array}{l}\text { Positive } \\
\text { selection } \\
(p<0.1)\end{array}$ & $\begin{array}{l}\text { Negative } \\
\text { selection } \\
(p<0.1)\end{array}$ & $\begin{array}{l}\text { Pervasive } \\
\text { diversifying } \\
\text { selection } \\
\text { (posterior } \\
\text { probability } \\
>0.9 \text { ) }\end{array}$ & $\begin{array}{l}\text { Pervasive } \\
\text { purifying } \\
\text { selection } \\
\text { (posterior } \\
\text { probability } \\
>0.9 \text { ) }\end{array}$ & $\begin{array}{l}\text { Episodic } \\
\text { diversifying } \\
\text { selection }\end{array}$ & Mean dN/dS & $\begin{array}{l}\text { Human } \\
\text { neurogenic } \\
\text { expression }^{\mathrm{a}}\end{array}$ & $\begin{array}{l}\text { Mouse } \\
\text { neurogenic } \\
\text { expression }^{a}\end{array}$ & $\begin{array}{l}\text { Allelic } \\
\text { expression }\end{array}$ \\
\hline Grb10 & 1 & 384 & 1 & 503 & 15 & 0.138 & No & Yes & Maternal \\
\hline Nnat & 0 & 27 & 0 & 65 & 1 & 0.04 & No & Yes & Paternal \\
\hline Osbpl5 & 10 & 361 & 2 & 630 & 19 & 0.181 & No & Yes & Maternal \\
\hline Peg10 & 4 & 156 & 3 & 239 & 26 & 0.162 & No & Yes & Paternal \\
\hline Peg12 & 3 & 55 & 1 & 117 & 11 & 0.349 & No & Yes & Paternal \\
\hline Plagl1 & 2 & 186 & 2 & 288 & 19 & 0.277 & No & Yes & Paternal \\
\hline Snrpn & 0 & 100 & 1 & 148 & 1 & 0.18 & No & Yes & Paternal \\
\hline Usp29 & 17 & 96 & 3 & 105 & 91 & 0.722 & No & Yes & Paternal \\
\hline
\end{tabular}

${ }^{a}$ Differentially expressed in a neocortical germinal zone. 